\title{
Suplementos múltiplos para novilhas de corte em pastejo no período seco
}

\section{Multiple supplements for beef heifers on pasture in dry season}

\author{
Renata Pereira da Silva-Marques ${ }^{1 *}$; Joanis Tilemahos Zervoudakis ${ }^{2}$; \\ Luciana Keiko Hatamoto-Zervoudakis ${ }^{2}$; Luciano da Silva Cabral'; \\ Emerson Alexandrino ${ }^{3}$; Alan Carlos Barboza Melo $;$; Juliane Quenoizoré Soares ${ }^{5}$; \\ Everton Riva Donida ${ }^{6}$; Lilian Chambó Rondena Pesqueira Silva ${ }^{7}$
}

\section{Resumo}

Objetivou-se avaliar níveis de suplementos múltiplos para novilhas de corte em pastejo restrito, sobre ganho médio diário (GMD), análise econômica e consumo de matéria seca (CMS), consumo de forragem (CFO), consumo de proteína bruta (CPB) e consumo de nutrientes digestíveis totais (CNDT). Para avaliação do desempenho e análise econômica foram utilizadas 20 novilhas Nelore com 328,45 \pm $35,32 \mathrm{~kg}$, em que foram avaliados os seguintes suplementos: controle (SAL) e níveis de suplementação de 2, 4 e $6 \mathrm{~kg} /$ animal/dia, perfazendo as seguintes proporções em \% do peso corporal (PC): 0,55; 1,11 e $1,66 \%$, respectivamente. Para avaliação do consumo de nutrientes foram utilizadas outras 5 novilhas Nelore com $344 \pm 21,10 \mathrm{~kg}$, em que foram avaliados os mesmos suplementos supracitados além do nível 2,22\% PCM ( $8 \mathrm{~kg} / \mathrm{animal} / \mathrm{dia})$. O GMD apresentou comportamento quadrático; os CMST, CPB e CNDT apresentaram comportamento linear crescente e o CMSF linear decrescente em função dos níveis de suplementos. A estratégia de fornecimento de $0,55 \%$ do PCM proporcionou o melhor retorno econômico. A suplementação de 0,$55 ; 1,11$ e 1,66\% do PCM para novilhas em pastejo restrito proporciona ganhos adicionais de peso de 608; 762 e $943 \mathrm{~g} /$ dia, respectivamente, os quais são efetivos em promover desempenhos produtivos e econômicos semelhantes aos obtidos em sistemas a pasto no período das águas.

Palavras-chave: Casca de soja, Brachiaria brizantha, efeito substitutivo, ganho de peso, suplementação

\footnotetext{
Abstract

The objective was to evaluate levels of multiple supplement for beef heifers in restricted grazing on average daily gain (ADG), economic analysis and intakes of total dry matter (TDMI), forage dry matter (FDMI), crude protein (CPI) and total digestible nutrients (TDNI). For evaluation of performance and economic analysis, twenty Nellore heifers $(328.45 \mathrm{~kg})$ were used. The following supplements were evaluated as fed to the animals: control (mineral supplement) and supplementation levels of 2, 4 and 6

${ }^{1}$ Discente de Doutorado em Ciência Animal, Universidade Federal de Mato Grosso, UFMT, Cuiabá, MT. E-mail: renatinharps@, hotmail.com

${ }^{2}$ Profs. Drs., Universidade Federal de Mato Grosso, UFMT, Cuiabá, MT. E-mail: joanis@ufmt.br; lukeiko@yahoo.com.br, cabralls@ufmt.br

3 Prof. Dr., Universidade Federal do Tocantins, UFT, Araguaína, TO. E-mail: e alexandrino@yahoo.com.br

4 Discente de Zootecnia, UFMT, Cuiabá, MT. E-mail: allan.a.b@hotmail.com

5 Discente de Mestrado em Ciência Animal, UFMT, Cuiabá, MT. E-mail: juliane_qs@hotmail.com

${ }^{6}$ Discente de Medicina Veterinária, UFMT, Cuiabá, MT. E-mail: evertonrd@hotmail.com

${ }^{7}$ Discente de Doutorado em Ciência Animal, UFMT, Cuiabá, MT. E-mail: lilianrondena@hotmail.com

* Autor para correspondência
} 
$\mathrm{kg} /$ animal/day, composing the following percentages of average body weight (ABW): $0.55,1.11$ and $1.66 \%$, respectively. To evaluate the nutrient intake, additional five Nellore heifers with $344 \mathrm{~kg}$, were used, which were submitted to same supplements previously mentioned, in addition to the level of $2.22 \%$ of $\mathrm{ABW}$ ( $8 \mathrm{~kg} /$ animal/day). Average daily gain showed quadratic behavior; TDMI, CPI and TDNI had increasing linear behavior; and FDMI showed decreasing linear behavior in function of the supplementation levels. The strategy of supplying $0.55,1.11$ and $1.66 \%$ of the ABW to heifers on restricted grazing provides additional weight gains of 608,762 and $943 \mathrm{~g} /$ day, respectively, which are effective in promoting similar productive and economic performance to those obtained in grazing systems in the rainy period.

Key words: Soybean hulls, Brachiaria brizantha, replacement effect, weight gain, supplementation

\section{Introdução}

No Brasil a bovinocultura se destaca pela competitividade econômica, pois a maioria do rebanho se alimenta basicamente de gramíneas forrageiras, as quais constitui a base de sustentação da pecuária de corte nacional (MORAES et al., 2006). No entanto, a produtividade e qualidade dessas gramíneas sofrem variação sazonal ao longo do ano devido às condições climáticas, não permitindo desempenho constante dos animais ao longo do ano, resultando em baixos índices zootécnicos (PAULINO et al., 2008).

O período da seca é a fase mais crítica do sistema de produção de bovinos em pastejo. Nesta época, o rebanho bovino alimenta-se de forragem de baixo valor nutritivo, caracterizadas por elevado teor de fibra indigerível e teores de proteína bruta inferiores ao nível crítico (7\% PB na dieta basal), limitando o seu consumo e, desta forma, o atendimento das necessidades nutricionais dos animais (REIS et al., 2005).

$\mathrm{Na}$ tentativa de viabilizar um plano nutricional que melhore os índices produtivos dos rebanhos e que, ao mesmo tempo, contribua para a redução de custos, diversas alternativas têm sido propostas, entre elas, a utilização de coprodutos da agroindústria, que em razão das características da composição bromatológica, forma física, disponibilidade e custo, apresentam diferenças quanto ao potencial de utilização na nutrição de ruminantes (SOUZA et al., 2006).

Essas estratégias de suplementação são importantes para manutenção de níveis produtivos mínimos em sistemas de pastejo de não equilíbrio. Para isso, recomenda-se o uso de suplementos de mínimo custo, o que pode ser obtido pela inclusão de coprodutos da lavoura, que serão utilizados em maior participação em sua formulação, "flexibilizando" maiores níveis de suplementação, com maior viabilidade econômica do processo. Dessa forma, são utilizados ingredientes como a casca de café, bagaço de cana de açúcar, feno de feijão guandu e casca de soja em estratégias em que se busca a manutenção no equilíbrio de nutrientes no metabolismo dos animais (ZERVOUDAKIS et al., 2011).

Deste modo, objetivou-se avaliar o desempenho produtivo, análise econômica econsumo denutrientes em novilhas de corte a pasto, suplementadas com diferentes níveis de fornecimento de suplementos múltiplos em sistemas com pouca oferta de forragem no período de seca.

\section{Material e Métodos}

Os experimentos foram conduzidos no setor de Bovinocultura de Corte da Fazenda Experimental da Faculdade de Agronomia, Medicina Veterinária e Zootecnia - FAMEVZ da Universidade Federal de Mato Grosso - UFMT, localizada no município de Santo Antônio do Leverger- Mato Grosso, próximo das coordenadas de $15^{\circ} 47^{\prime} 5^{\prime \prime}$ Sul e $56^{\circ} 04^{\prime}$ Oeste, com altitude de 140 metros, no período da seca, entre os meses de agosto a novembro de 2010. O clima da região é do tipo Aw de acordo com a classificação 
Köppen, ou seja, clima tropical, megatérmico, com inverno seco e chuvas no verão (Tabela 1).

Para avaliação do desempenho produtivo e análise econômica (Experimento 1- Exp. 1), foram utilizadas 20 novilhas Nelores, com idade e pesos médios iniciais de 22 meses e 328,45 $\pm 35,32 \mathrm{~kg}$, respectivamente. Os animais foram estratificados com base no peso corporal (PC) e distribuídos em quatro lotes com pesos semelhantes. Para avaliação do consumo foram utilizadas outras cinco novilhas Nelores (Experimento 2- Exp. 2), contemporâneas dos animais do Exp. 1, com idade e pesos médios iniciais de e 22 meses $344,00 \pm 21,10$ $\mathrm{kg}$, respectivamente, mantidas em área anexa aos piquetes do Exp.1.

Tabela 1. Valores médios das temperaturas máximas e mínimas, umidade relativa do ar e precipitação pluviométrica, coletadas durante o período experimental.

\begin{tabular}{|c|c|c|c|c|}
\hline \multirow{2}{*}{ Mês } & \multicolumn{2}{|c|}{ Temperatura média $\left({ }^{\circ} \mathrm{C}\right)$} & \multirow{2}{*}{$\begin{array}{c}\text { Umidade Relativa } \\
\text { do ar }(\%)\end{array}$} & \multirow{2}{*}{ Precipitação (mm) } \\
\hline & Máxima & Mínima & & \\
\hline Agosto & 35,8 & 15,0 & 54,5 & 0,0 \\
\hline Setembro & 35,8 & 20,9 & 50,0 & 9,5 \\
\hline Outubro & 35,1 & 21,7 & 64,5 & 73,2 \\
\hline Novembro & 33,1 & 19,8 & 74,7 & 184,4 \\
\hline
\end{tabular}

Fonte: Estação Agrometeorológica Fazenda Experimental.

A área experimental destinada aos animais foi constituída de quatro piquetes de 1,45 ha cada (Exp. 1) e cinco piquetes de 0,24 ha cada (Exp. 2), ambos cobertos uniformemente com Brachiaria brizanha cv. Marandu, providos de bebedouros e cochos cobertos $(60 \mathrm{~cm} /$ animal) para fornecimento do suplemento.

Foram avaliados suplementos múltiplos e mineral (controle) (Tabela 2), com fornecimento de $2 ; 4 ; 6$ e $8 \mathrm{~kg} /$ dia, perfazendo níveis de fornecimento de: 0,$55 ; 1,11 ; 1,66$ e 2,22\% do peso corporal médio (PCM) das novilhas, respectivamente, calculados de acordo com as exigências para fêmeas Nelore em confinamento, objetivando ganho médio diário (GMD) de 500 g/animal/dia (VALADARES FILHO; PAULINO; MAGALHÃES, 2006).

Tabela 2. Composição dos suplementos ofertados aos animais.

\begin{tabular}{ccccccc}
\hline \multirow{2}{*}{ Ingrediente } & \multirow{2}{*}{$\mathrm{SM}^{1}$} & \multicolumn{4}{c}{ Suplementos $^{2}$} & \multirow{2}{*}{$\mathrm{R} \$ / \mathrm{Kg}$} \\
\cline { 3 - 5 } & & 2 & 4 & 6 & $8^{*}$ & \\
Casca soja & - & 500,0 & 500,0 & 540,0 & 560,0 & 0,25 \\
Milho grão triturado & - & 160,0 & 170,0 & 150,0 & 160,0 & 0,26 \\
Farelo de girassol & - & 100,0 & 100,0 & 100,0 & 103,7 & 0,26 \\
Farelo soja & - & 145,0 & 177,5 & 175,0 & 150,0 & 0,68 \\
Uréia: Sulfato de Amônia 9:1 & - & 45,0 & 22,5 & 15,0 & 11,3 & 1,24 \\
Mistura mineral $^{1}$ & 1000,0 & 50,0 & 30,0 & 20,0 & 15,0 & 1,38 \\
\hline
\end{tabular}

${ }^{1} \mathrm{SM}$ - Suplemento mineral comercial: Níveis de garantia: cálcio $198 \mathrm{~g}$; fósforo $87 \mathrm{~g}$; sódio 97,6g; magnésio 5,1g; enxofre $12 \mathrm{~g}$; iodo $17,7 \mathrm{mg}$; ferro $280 \mathrm{mg}$; selênio $18 \mathrm{mg}$; cobalto $80 \mathrm{mg}$; manganês $527 \mathrm{mg}$; flúor $870 \mathrm{mg}$; cobre $1.250 \mathrm{mg}$ e zinco $3.500 \mathrm{mg}$.\%

${ }^{2}$ Níveis de fornecimento de suplementos de 0,$55 ; 1,11 ; 1,66$ e $2,22 \%$ do peso corporal para $2,4,6$ e $8 \mathrm{~kg} /$ animal/dia, respectivamente ( $\mathrm{g} / \mathrm{kg}$ de matéria natural).

* Suplemento 2,22\%PCM fornecido somente para os animais do Experimento 2.

Fonte: Elaboração dos autores. 
A variação na composição dos suplementos foi decorrente da fixação no consumo de ureia $(90 \mathrm{~g} /$ animal/dia) e da inclusão de aproximadamente 50\% de casca de soja (Tabela 2), que pelo seu elevado teor em fibra potencialmente digestível, foi utilizada como fonte volumosa com intuito de substituir a fração volumosa da dieta dos animais, uma vez que nos piquetes havia limitada oferta de matéria seca de forragem.

Os suplementos foram fornecidos diariamente em dois horários: 50\% às dez horas da manhã e 50\% às três horas da tarde.

Os animais (Exp. 1) foram pesados no início (05/08) e final da adaptação (inicio do experimento-16/08) e final do experimento (09/11) após jejum hídrico e de sólidos de 14 horas. Após a pesagem inicial $(05 / 08)$ as novilhas foram submetidas ao sorteio dos suplementos. A adaptação teve duração de 11 dias, em que, no $1^{\circ} \mathrm{e}$ $2^{\circ}$ dia todos os lotes receberam a mesma quantidade de suplemento ( $2 \mathrm{~kg} /$ animal $/ \mathrm{dia})$, do $5^{\circ}$ ao $7^{\circ}$ dia, os animais do lote 4 e $6 \mathrm{~kg}$ receberam $4 \mathrm{~kg} /$ animal/ dia e do $8^{\circ}$ dia em diante as novilhas do lote $6 \mathrm{~kg}$ receberam $6 \mathrm{~kg}$ de suplemento.

No Exp. 2, os primeiros nove dias de cada período foram destinados à adaptação dos animais ao suplemento (no $1^{\circ}$ e $2^{\circ}$ dia todos os animais receberam $2 \mathrm{~kg}$ de suplemento, do $3^{\circ}$ ao $5^{\circ}$ dia os animais do suplemento 4, 6 e $8 \mathrm{~kg}$ receberam $4 \mathrm{~kg} /$ dia, no $7^{\circ}$ e $8^{\circ}$, as novilhas do suplemento 6 e $8 \mathrm{~kg}$ receberam $6 \mathrm{~kg} /$ dia e do $9^{\circ}$ dia em diante os animais do suplemento 8 , receberam $8 \mathrm{~kg}$ de suplemento) e os onze dias restantes para a realização das coletas. A cada final de período, durante a avaliação nutricional, as novilhas foram pesadas, sem jejum, para acompanhamento do desempenho e do consumo em função do peso corporal.

O Exp. 1 foi conduzido em três períodos de 28 dias cada ( $1^{\circ}$ Período: 16/08-12/09; $2^{\circ}$ Período: 13/09-10/10 e $3^{\circ}$ Período: 11/10-8/11), sendo que o ganho médio diário (GMD) e o ganho de peso total (GPT) foram obtidos pela diferença entre o peso final e o inicial, com jejum prévio. O Exp.2 foi conduzido em cinco períodos de 20 dias de duração cada, sendo os primeiros nove dias de cada período destinados à adaptação dos animais e os onze dias restantes para coletas.

No primeiro dia de cada período (Exp. 1 e 2) foram realizadas coletas de amostras de forragem nos diferentes piquetes, através do corte, a $5 \mathrm{~cm}$ do solo, de três áreas delimitadas por um quadrado metálico de 0,5 x 0,5 m, escolhidos na altura média da forragem (50 pontos em cada diagonal) para a estimação da massa de forragem e a matéria seca potencialmente digestível (MSpD).

Após a coleta, as amostras de forragem de cada piquete foram pesadas, homogeneizadas e retiradas duas alíquotas: para avaliação da massa de forragem/ha e fracionamento dos componentes estruturais da planta para análise das disponibilidades/ha de matéria seca de lâmina foliar verde (MSLFV), lâmina foliar seca (MSLFS), pseudocolmo verde (MSPV) e pseudocolmo seco (MSPS). A amostragem da forragem consumida pelos animais foi obtida via simulação manual do pastejo, realizada no $1^{\circ}$ dia de cada período experimental. As amostras foram pesadas após as coletas e congeladas a $-20^{\circ} \mathrm{C}$ sendo posteriormente secas em estufa $\left(65^{\circ} \mathrm{C}\right)$, moídas em moinho tipo Willey (peneira de malha de 1,0 mm), para posterior análises bromatológicas.

As estimativas de oferta de massa de forragem, lâmina foliar, matéria seca potencialmente digestível ( $\mathrm{kg}$ MS/100 $\mathrm{kg} \quad \mathrm{PC}$ ) foi calculada utilizando-se a média da massa de forragem total dos piquetes em cada período dividido pela média do ganho de peso corporal total dos animais mantidos no piquete no mesmo período.

Das amostras destinadas à estimativa da massa de forragem (MF), foi determinado o resíduo insolúvel em detergente neutro, obtido após incubação in situ das amostras por 240 horas (FDNi) (CASALI et al., 2008), para cálculo do percentual de MSpD aos animais. 
Nas amostras de pastejo simulado foram realizadas as determinações da matéria seca, matéria orgânica, proteína bruta, extrato etéreo, matéria mineral (SILVA; QUEIROZ, 2002). As avaliações de fibra em detergente neutro (FDN), fibra em detergente neutro corrigida para cinzas e proteína (FDNcp) e fibra em detergente ácido (FDA) foram realizadas de acordo com Van Soest, Robertson e Lewis (1991).

Os carboidratos totais (CT) das amostras foram calculados segundo metodologia descrita por Sniffen et al. (1992), em que CT( $\%)=100$ - (\%PB + $\%$ EE + \%Cinzas). A quantificação dos carboidratos não fibrosos (CNF) dos suplementos foi realizada de acordo com adaptação de Hall (2000), em virtude da inclusão de uréia na composição dos suplementos.

Os teores de nutrientes digestíveis totais (NDT) foram estimados segundo o NRC (2001) com base na composição químico-bromatológica dos alimentos, por intermédio da equação: NDT (\%) = $(\mathrm{PBD}+\mathrm{CNFD}+\mathrm{FDNpD}+\mathrm{EED} \times 2,25)-7$, onde a constante 7 refere-se ao valor metabólico fecal. Os valores de proteína bruta digestível (PBD), ácidos graxos digestíveis (AGD), fibra em detergente neutro corrigida para proteína digestível (FDNpD) e carboidratos não fibrosos digestíveis (CNFD) foram estimados de acordo com as equações (NRC, 2001):

Para estimar a excreção fecal (Exp. 2) foram fornecidos para cada novilha diariamente $10 \mathrm{~g}$ do indicador externo óxido crômico $\left(\mathrm{Cr}_{2} \mathrm{O}_{3}\right)$ acondicionado em cartucho de papel e introduzido no esôfago dos animais às 11 horas, com auxílio de uma mangueira, entre o $10^{\circ}$ e $16^{\circ}$ dia de cada período experimental, sendo as amostras de fezes coletadas no reto dos animais no $15^{\circ}$ (16 horas), $16^{\circ}$ (12 horas) e $17^{\circ}$ dia (08 horas). Estas foram acondicionadas em sacos plásticos e congeladas a $-20^{\circ} \mathrm{C}$. Posteriormente, foram secas $\left(65^{\circ} \mathrm{C}\right)$ e moídas em moinho tipo Willey (peneira com malha de 1,0 mm). As amostras dos diferentes horários de coleta formaram uma amostra composta para cada animal.

A excreção de matéria seca fecal foi estimada (g/dia) pela relação entre a quantidade fornecida do indicador ( $\mathrm{g}$ ) e sua concentração nas fezes ( $\mathrm{g} /$ kg) (BURNS; POND; FISHER, 1994). Para a obtenção de estimativas do consumo voluntário de matéria seca (DETMANN et al., 2001), utilizou-se a FDNi como indicador interno. Para isso, amostras de pastejo simulado, suplementos e fezes foram incubadas no rúmen por meio de sacos de tecido não tecido (TNT) durante 240 horas (CASALI et al., 2008).

A avaliação econômica (Exp. 1) foi realizada tendo em vista a remuneração do capital investido, dividindo-se a margem de lucro pelo investimento total envolvido no processo de suplementação, considerando o rendimento de carcaça de 52\%.

A receita foi obtida por meio da multiplicação do ganho em equivalente carcaça pelo valor da arroba na região ( $\mathrm{R} \$ 94,79)$, e as despesas foram obtidas por meio do custo total com pasto $(15 \%$ do valor médio da arroba durante o período + custos: operacional, sanidade, mão-de-obra (R\$ 0,128/ dia)); custo com suplemento (valor do quilograma) e custo com os animais com atualização do início até o fim do Exp.1 em relação à taxa de juros $(0,6 \%$ / mês). Todas as cotações empregadas foram tomadas no Estado de Mato Grosso e no período de condução deste experimento.

Depois de obtidos os resultados da avaliação econômica, foram gerados possíveis cenários para estes indicadores a partir do coeficiente de variação de algumas variáveis.

Foi feita uma simulação de possíveis cenários que podem ocorrer considerando a variação de preço da arroba da vaca de $\mathrm{R} \$ 55,00$ a $\mathrm{R} \$ 100,00$, visto que a série histórica dos preços praticados entre os anos de 2008 a 2013 foram de $\mathrm{R} \$ 65,00$ a R \$ 82,00 ; e variação no preço do suplemento $(\mathrm{kg})$ de $\mathrm{R} \$ 0,40$ a R\$ 1,30 , na região onde foi desenvolvida 
a pesquisa, por serem estas as variáveis que mais impactam no resultado da avaliação econômica nesta pesquisa.

A partir dos resultados da avaliação econômica para os suplementos em função dos resultados das médias de desempenho dos animais submetidos a cada dieta experimental, obtiveram-se as médias gerais, as quais foram submetidas às simulações dos possíveis cenários, substituindo o valor da arroba e do suplemento encontrados para cada cenário gerando assim, seis simulações de viabilidade econômica para cada cenários, sendo eles o melhor, pior, médio, mais provável, otimista e pessimista.

O cenário melhor foi gerado considerando-se o máximo preço praticado no mercado pela arroba do boi e o mínimo preço do suplemento $(\mathrm{kg})$; o pior cenário foi gerado considerando-se o mínimo preço praticado pela arroba e o máximo preço do suplemento $(\mathrm{kg})$; o cenário médio foi gerado considerando-se as médias dos preços de ambas variáveis; o cenário mais provável foi gerado considerando-se os o preço das variáveis que ocorrem com maior frequência; o cenário otimista foi gerado considerando-se as médias do preço da variável arroba do boi, adicionado do percentual do coeficiente de variação $(+19,53 \%)$ obtido a partir da série de preços coletados e ainda subtraído do coeficiente de variação $(-35,10 \%)$ da série de preços referente ao suplemento. $\mathrm{O}$ cenário pessimista foi gerado considerando-se as médias do preço da variável arroba do boi, subtraído do percentual do coeficiente de variação (-19,53\%) obtido a partir da série de preços coletados e ainda adicionado o percentual do coeficiente de variação $(+35,10 \%)$ da série de preços referente ao suplemento.
O lucro dos cenários foi obtido a partir do lucro dos animais suplementados subtraído ao lucro dos animais controle (suplemento mineral).

O experimento 1 foi estruturado em delineamento inteiramente casualizado e o experimento $2 \mathrm{em}$ quadrado latino $5 \times 5$. Os dados foram submetidos à análise de variância (ANOVA). Quando constatada diferença entre as médias, foi realizada a análise de regressão polinomial. Para as análises estatísticas, foi utilizado o programa estatístico SAS (Versão 9.2, 2001), adotando-se nível de significância de 5\%.

\section{Resultados e Discussão}

O pasto apresentou altura média de $15,24 \mathrm{~cm} \mathrm{e}$ massa de forragem (MF) média de 1708,56 kg MS/ ha (Figura 1) nos piquetes experimentais. É possível observar que ao início do experimento a MF de lâmina foliar verde foi de $69,06 \mathrm{~kg} / \mathrm{ha}$ e que ao final do período experimental essa disponibilidade aumentou para $182,11 \mathrm{~kg} / \mathrm{ha}$, representando aumento de $163,70 \%$.

O manejo da pastagem foi conduzido de forma que a oferta de forragem dos piquetes não interferisse na resposta dos suplementos, ou seja, não possibilitou que os animais do tratamento controle adquirissem ganho de peso compensatório, uma vez que, os animais permaneceram nos mesmos piquetes do início ao final do experimento. Se houvesse rodízio dos animais entre os piquetes, as novilhas do grupo controle seriam favorecidas, visto que as dos demais piquetes estavam recebendo suplemento concentrado no cocho de 2,4 e $6 \mathrm{~kg} /$ animal/dia. No entanto não foram observadas diferenças na massa de matéria seca entre os mesmos. Sendo assim, o valor médio observado para oferta de MS de forragem foi de $5,02 \mathrm{~kg}$ de $\mathrm{MS} / 100 \mathrm{~kg}$ de peso corporal (PC) (Figura 2). 
Figura 1. Valores médios de massa de forragem (MF), MS potencialmente digestível (MSpD), MS de lâmina foliar verde (MLFV), MS de lâmina foliar seca (MPFS), MS de pseudocolmo verde (MPCV) e MS de pseudocolmo seco (MPCS) de Brachiaria brizantha cv. Marandu nos períodos experimentais.

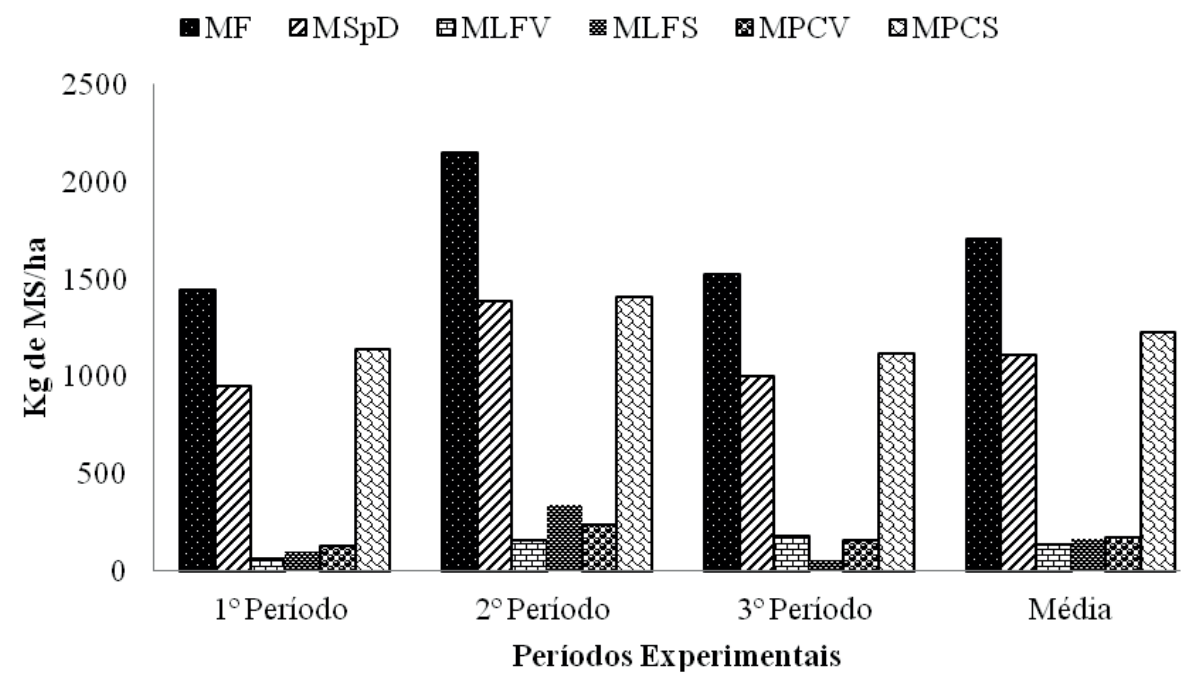

Fonte: Elaboração dos autores.

Figura 2. Valores médios de oferta de matéria seca de forragem (MF), matéria seca potencialmente digestível (MSpD), matéria seca de lamina foliar verde (MLFV) matéria seca de lamina foliar seca (MLFS), matéria seca de pseudocolmo verde (MPCV), matéria seca de pseudocolmo seco (MPCS) em kg MS/100 kg de PC da pastagem de Brachiaria rizantha, cv. Marandu durante os períodos experimentais.

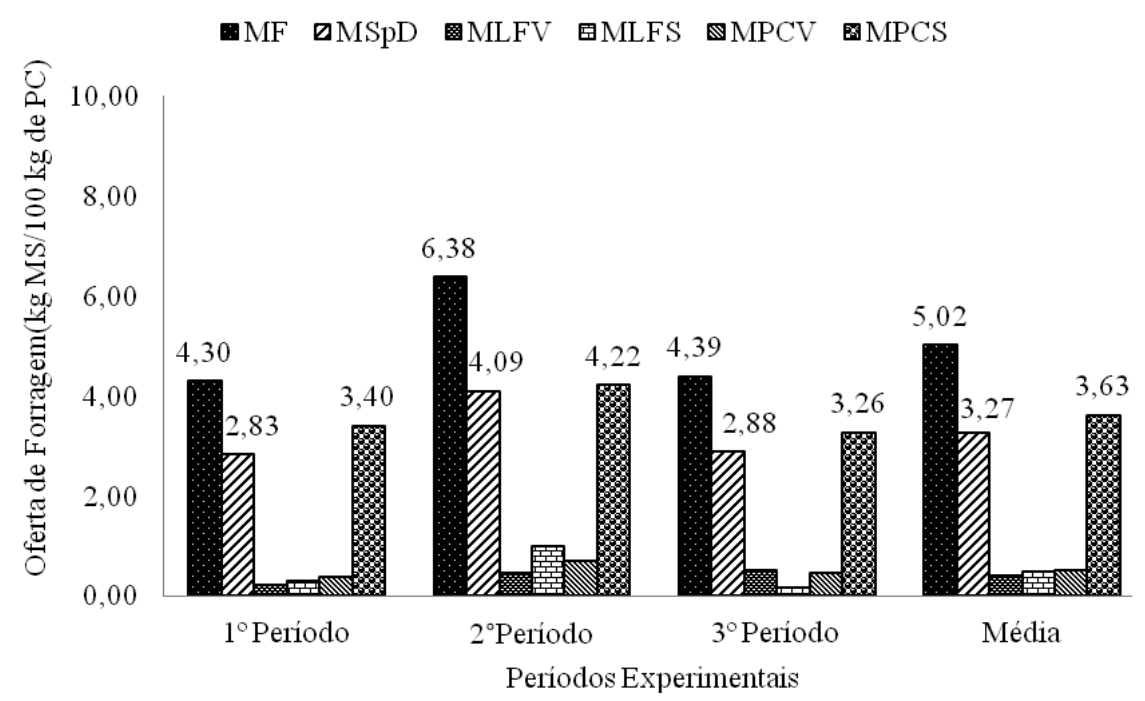

Fonte: Elaboração dos autores.

A disponibilidade média de $\mathrm{MSpD}$ durante o experimento foi correspondente a $65,10 \%$ da $\mathrm{MF}$, o que proporcionou uma oferta média de MSpD, de 3,27 kg/100 kg de PC/animal/dia (Figura 2). Deste modo, pode-se inferir que esses valores não permitiram a seletividade animal e, consequentemente, proporcionaram efeito negativo no desempenho dos animais recebendo apenas mistura mineral. 
Além disso, pode-se observar que o acúmulo redução das lâminas foliares (Figura 1), acarretando de matéria seca de forragem (Figuras 1 e 2) é na baixa relação lâmina foliar:pseudocolmo $(0,22)$ acompanhado do aumento de pseudocolmos e (Figura 3).

Figura 3. Proporção dos componentes bromatológicos (matéria seca de lâmina foliar verde (MLFV) matéria seca de lâmina foliar seca (MLFS), matéria seca de pseudocolmo verde (MPCV), matéria seca de pseudocolmo seco (MPCS)) da massa de forragem da pastagem de Brachiaria rizantha, cv. Marandu durante os períodos experimentais.

\section{田MLFV $\square \mathrm{MLFS}$ 图MPCV $\triangle \mathrm{MPCS}$}

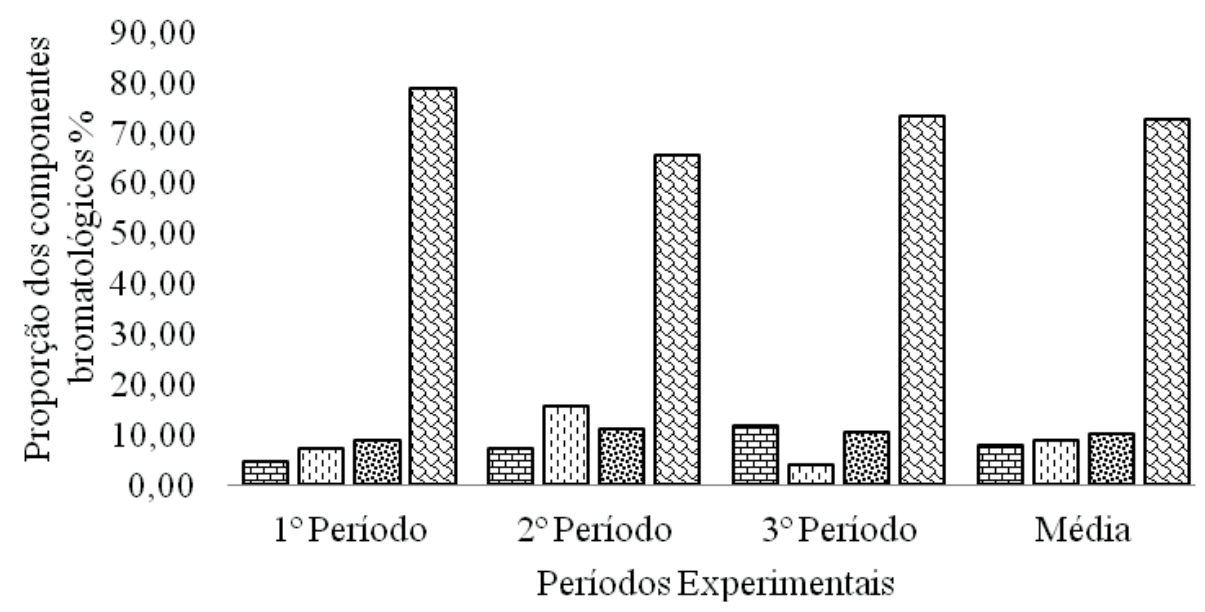

Fonte: Elaboração dos autores.

Apesar da baixa relação lâmina (REIS et al., 2005). Além disso, pode-se constatar foliar:pseudocolmo, a amostra de pasto obtida via simulação manual de pastejo apresentou elevada quantidade de proteína bruta (PB), de $68,45 \mathrm{~g} / \mathrm{kg}$ de MS (Tabela 3), valor considerado como alto para o período seco. Este valor pode ser justificado pela ocorrência de chuvas no período (Tabela 1), que proporcionou aumento na matéria seca de lâmina foliar verde durante os períodos experimentais (Figura 1), contribuindo assim para o aumento na quantidade de PB. No entanto, este valor de PB está aquém do considerado como nível crítico para satisfazer as exigências microbianas em compostos nitrogenados (7\% PB na dieta basal) e permitir a fermentação dos carboidratos fibrosos no rúmen que a forragem apresentou quantidades de FDN e FDNi de 664,4 e 225,1 g/kg de MS, respectivamente, que implicaria em redução no conteúdo celular e redução nos teores de nitrogênio da forragem disponível aos animais.

Devido às características qualitativas (Tabela 3) e quantitativas (Figura 1) apresentadas pelo pasto, os animais responderam positivamente ao fornecimento de suplementos múltiplos $(\mathrm{P}<0,001)$, o que correspondeu ao incremento médio de $770 \mathrm{~g} /$ animal/dia em comparação àqueles animais recebendo apenas suplementação mineral (-179 g/ animal/dia) (Tabela 4). 
Tabela 3. Composição nutricional dos suplementos e da forragem.

\begin{tabular}{|c|c|c|c|c|c|}
\hline \multirow{2}{*}{ Item } & \multicolumn{4}{|c|}{ Suplementos $^{1}$} & \multirow{2}{*}{ Forragem } \\
\hline & 2 & 4 & 6 & 8 & \\
\hline Matéria seca ${ }^{2}$ & 862,5 & 878,4 & 886,7 & 890,7 & 489,2 \\
\hline Matéria mineral $^{3}$ & 45,0 & 47,2 & 49,1 & 49,0 & 97,4 \\
\hline Proteína bruta ${ }^{3}$ & 340,3 & 294,5 & 282,0 & 268,8 & 68,45 \\
\hline Extrato etéreo $^{3}$ & 22,7 & 23,7 & 23,8 & 24,3 & 24,5 \\
\hline Carboidratos totais $^{3}$ & 616,2 & 641,7 & 649,9 & 661,6 & 794,9 \\
\hline $\mathrm{FDN}^{3}$ & 343,5 & 355,0 & 371,6 & 376,0 & 664,4 \\
\hline $\mathrm{FDA}^{3}$ & 238,9 & 245,8 & 258,9 & 262,2 & 401,8 \\
\hline $\mathrm{FDNcp}^{3}$ & 304,1 & 315,2 & 329,2 & 332,4 & 619,9 \\
\hline $\mathrm{FDNi}^{3}$ & 63,0 & 64,5 & 65,8 & 67,3 & 225,1 \\
\hline Nitrogênio insolúvel em detergente neutro ${ }^{4}$ & 281,9 & 284,5 & 300,3 & 310,3 & 330,3 \\
\hline Nitrogênio insolúvel em detergente ácido ${ }^{4}$ & 92,1 & 93,2 & 98,6 & 101,8 & 298,7 \\
\hline Carboidratos não fibrosos ${ }^{3}$ & 283,9 & 298,2 & 290,4 & 297,9 & 180,1 \\
\hline Nutrientes digestíveis totais estimados ${ }^{3}$ & 433,8 & 456,1 & 454,3 & 461,1 & 470,29 \\
\hline
\end{tabular}

${ }^{1}$ Níveis de fornecimento de suplementos de 0,$55 ; 1,11 ; 1,66$ e 2,22\% do peso corporal para 2, 4, 6 e $8 \mathrm{~kg} /$ animal/dia, respectivamente; ${ }^{2}(\mathrm{~g} / \mathrm{kg}$ de matéria natural $) ;{ }^{3}(\mathrm{~g} / \mathrm{kg}$ de $\mathrm{MS}) ;{ }^{4}(\mathrm{~g} / \mathrm{kg}$ de nitrogênio total $) ;$

* Suplemento 8 fornecido somente para os animais do Experimento 2.

Fonte: Elaboração dos autores.

Tabela 4. Valores médios de consumo dos suplementos, peso corporal inicial (PCi) e final (PCf), ganho de peso total (GPT) e ganho médio diário (GMD) de novilhas do Experimento 1.

\begin{tabular}{|c|c|c|c|c|c|c|c|c|}
\hline \multirow{2}{*}{ Variáveis } & \multirow{2}{*}{$\mathrm{SM}^{1}$} & \multicolumn{3}{|c|}{ Suplementos } & \multirow{2}{*}{ Regressão } & \multirow{2}{*}{ DP } & \multirow{2}{*}{$\mathrm{R}^{2}$} & \multirow{2}{*}{$\mathrm{CV}(\%)$} \\
\hline & & 2 & $4^{2}$ & 6 & & & & \\
\hline Consumo $^{3}$ & 0,016 & 2,00 & 4,00 & 5,87 & & - & & - \\
\hline PCi (kg) & 309,6 & 334,8 & 335,8 & 333,6 & & $\pm 7,89$ & & 10,75 \\
\hline PCf $(k g)$ & 294,6 & 370,8 & 384,8 & 397,8 & & $\pm 11,60$ & & 14,36 \\
\hline GPT (kg) & $-15,0$ & 37,2 & 49,0 & 64,2 & & $\pm 7,14$ & & 95,16 \\
\hline GMD (kg) & $-0,179$ & 0,429 & 0,583 & 0,764 & $\begin{array}{c}\hat{Y}=-0,155+ \\
0,309 \mathrm{X}-0,027 \mathrm{X}^{2}\end{array}$ & $\pm 0,38$ & 0,89 & 95,16 \\
\hline
\end{tabular}

${ }^{1}$ Suplemento mineral comercial; ${ }^{2}$ Níveis de fornecimento de suplementos de 0,$55 ; 1,11$ e $1,66 \%$ do peso corporal para 2,4 e $6 \mathrm{~kg} /$ animal/dia, respectivamente; ${ }^{3}$ Consumo de suplemento (kg/animal $\left./ \mathrm{dia}\right)$

Fonte: Elaboração dos autores.

O GMD apresentou comportamento quadrático $(\mathrm{P}<0,0001)$ (Tabela 4), com resposta máxima estimada para a suplementação de $5,8 \mathrm{~kg} / \mathrm{animal}$, a qual propiciaria ganho de $0,741 \mathrm{~kg} / \mathrm{animal} / \mathrm{dia}$. A redução no desempenho à partir deste nível pode ser explicada pela elevada fermentabilidade da FDN presente na casca de soja associada ao pequeno tamanho da partícula da casca do grão de soja. Alguns pesquisadores (MERTENS, 1997;
IPHARRAGUERRE et al., 2002), indicaram que a casca de soja diminui a fibra fisicamente efetiva quando fornecida em teores acima de $30 \%$ da MS, e poderia elevar a concentração de acido no rúmen e diminuir a ingestão pelos animais.

A grande quantidade de fibra facilmente fermentescível no rúmen presente na casca de soja permite maior extensão de fermentação ruminal, o que favorece maior concentração de ácidos graxos 
de cadeia curta no rúmen quando comparada a rações com altos teores de forragens (SARWAR; FIRKINS; EASTRIDGE, 1992). De acordo com Ipharraguerre e Clark (2003), a substituição de fontes de forragem pela casca de soja, em valores de 5 ate $25 \%$ da MS total da ração, aumentou a proporção molar de propionato, sem afetar a proporção molar de acetato e butirato. Por outro lado, em rações contendo menos que 50\% de volumoso, a inclusão de CS reduziu a proporção de acetato (SARWAR; FIRKINS; EASTRIDGE, 1992) e butirato (CUNNINGHAM; CECAVA; JOHNSON, 1993).

Nesse contexto, a rápida disponibilização de glicose livre oriunda do processo de fermentação aumenta a osmolaridade do conteúdo ruminal, inibindo assim a absorção de ácidos graxos voláteis (AGV's) e exacerbando o acumulo de ácidos no rúmen (OWENS, 2007).

$\mathrm{O}$ acumulo dos ácidos diminui o $\mathrm{pH}$ ruminal, então, várias cepas de bactérias sensíveis a variação do $\mathrm{pH}$ do rúmen, não sobrevivem. A lise bacteriana aumenta os níveis de endotoxinas ruminais (NOCEK, 1997), acarretando em aumento do Lipopolissacarídeo (LPS) presentes na membrana das bactérias Gram-negativas. Com a liberação dos LPS na corrente sanguínea, o organismo em resposta, desencadeia a resposta inflamatória por ativar o sistema imune e promover a sintomatologia clínica de laminite (AMETAJ; ZEBELI; IQBAL, 2010). Além disso, a elevada pressão osmótica no rúmen, sentida pela parede do retículo-ruminal, inibe a ingestão de alimentos e digestão bacteriana de fibra e de amido (CARTER; GROVUM, 1990).

As estratégias de suplementação promoveram redução no consumo de forragem (CFO) dos animais contemporâneos (Exp. 2), ou seja, a ingestão de forragem apresentou comportamento linear decrescente $(\mathrm{P}<0,0001)$ em função dos níveis de fornecimento de suplementos (Tabela 5). Essa redução no $\mathrm{CFO}$ verificada por animais recebendo o mesmo nível de suplementação possibilita inferências relacionadas à baixa capacidade de tamponamento ruminal, ou seja, o elevado consumo de concentrado provocou o efeito substitutivo, em que os animais deixaram de ingerir forragem, com isso, comprometeu a ruminação e consequentemente a produção de saliva. Isso acarretou posteriormente em sinais clínicos de laminite e redução no ganho de peso médio diário de dois animais do lote de $6 \mathrm{~kg}$ de suplementação do Exp. 1.

Tabela 5. Valores médios de consumo de suplemento (CS), matéria seca (CMS), matéria seca de forragem (CFO) proteína bruta (CPB) e Nutrientes Digestíveis Totais (CNDT) em novilhas do Experimento 2.

\begin{tabular}{|c|c|c|c|c|c|c|c|c|}
\hline \multirow{2}{*}{ Variáveis } & \multirow{2}{*}{$\mathrm{SM}^{1}$} & \multicolumn{4}{|c|}{ Suplementos $^{2}$} & \multirow{2}{*}{ Regressão } & \multirow{2}{*}{$\mathrm{R}^{2}$} & \multirow{2}{*}{$\mathrm{CV}(\%)$} \\
\hline & & 2 & 4 & 6 & 8 & & & \\
\hline $\mathrm{CS}^{3}$ & 0,05 & 2,00 & 3,54 & 5,32 & 6,41 & & - & - \\
\hline $\mathrm{CMS}^{3}$ & 5,30 & 6,48 & 6,92 & 8,99 & 8,31 & $\hat{Y}=4,98+0,495 X$ & 0,54 & 19,00 \\
\hline $\mathrm{CFO}^{3}$ & 5,30 & 4,66 & 3,70 & 4,17 & 2,50 & $\hat{Y}=4,80-0,327 X$ & 0,44 & 33,32 \\
\hline $\mathrm{CPB}^{3}$ & 0,54 & 1,04 & 1,21 & 1,61 & 1,66 & $\hat{\mathrm{Y}}=552,38+157,287 \mathrm{X}$ & 0,67 & 28,15 \\
\hline $\mathrm{CNDT}^{3}$ & 2,68 & 3,70 & 4,31 & 5,72 & 5,68 & $\hat{Y}=2560,32+434,969 X$ & 0,81 & 14,04 \\
\hline
\end{tabular}

${ }^{1}$ Suplemento mineral comercial; ${ }^{2}$ Níveis de fornecimento de suplementos de 0,$55 ; 1,11 ; 1,66$ e 2,22\% do peso corporal para $2,4,6$ e $8 \mathrm{~kg} /$ animal $/$ dia, respectivamente; ${ }^{3} \mathrm{~kg} / \mathrm{animal} / \mathrm{dia}$.

Indicadores Econômicos

Fonte: Elaboração dos autores. 
Adicionalmente, a redução no $\mathrm{CFO}$ com o fornecimento de alto nível de suplementos é extremamente interessante, pois acarreta em redução da pressão de pastejo, o que é desejável em condições de oferta de pasto limitada.

Além disso, o melhor desempenho dos animais suplementados (Figura 4) está relacionado a maior ingestão de suplemento, que consequentemente favoreceu o aumento nos consumos de matéria seca, de proteína bruta (CPB) e nutrientes digestíveis totais (CNDT), ou seja, apresentaram comportamento linear crescente $(\mathrm{P}<0,0001)$ em função dos níveis de fornecimento de suplementos (Tabela 5). Este efeito observado sobre o CPB e CNDT pode ser devido às maiores concentrações destes nutrientes no suplemento em relação à forragem (PAULA et al., 2014). Sendo assim, evidencia-se a importância de se estabelecer estratégias de fornecimento de nutrientes para se viabilizar a produção intensiva de bovinos em sistemas de pastejo restrito (sistema de pastejo de não equilíbrio), visto que o desempenho animal depende inteiramente do consumo de matéria seca digestível.

Figura 4. Ganho de peso diário em novilhas suplementadas.

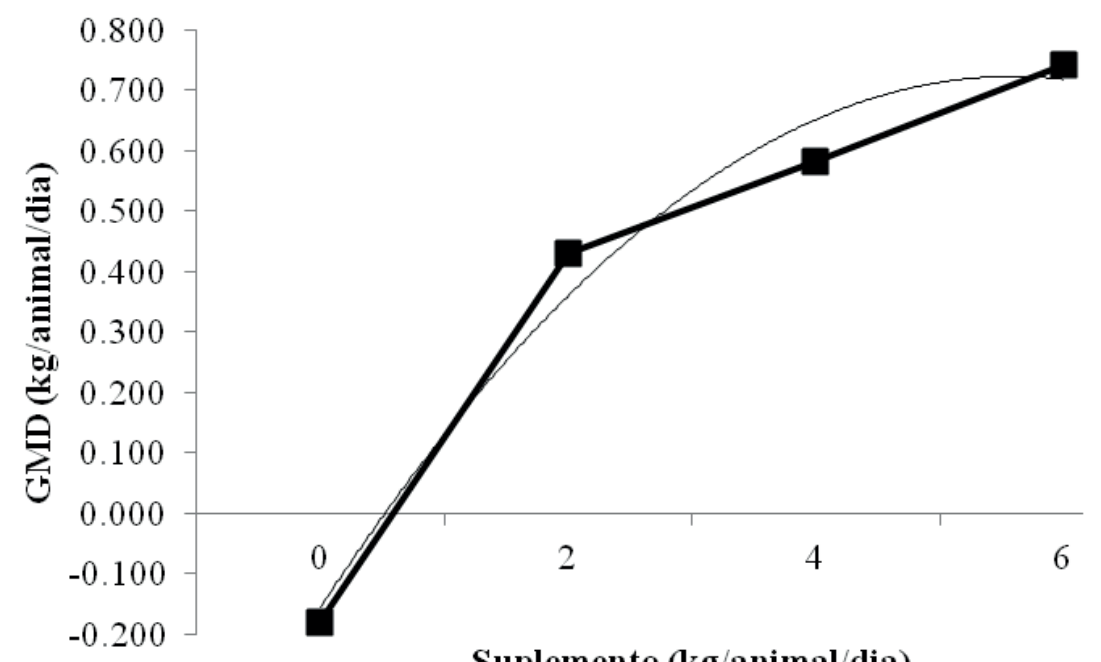

Suplemento (kg/animal/dia)

Fonte: Elaboração dos autores.

Este f está de acordo com afirmações de ElMemari Neto et al. (2003) que trabalharam com níveis de 0,7 e $1,4 \%$ PC de fornecimento de suplementos para novilhos Nelore em pastejo e obtiveram GMD de 0,489 e 0,645 kg/animal/dia, respectivamente, devido a baixa oferta de forragem, de $2,6 \%$ do PC.

Tão importante quanto à observação do ganho de peso dos animais são as avaliações econômicas, que são o referencial do pecuarista para a continuidade e difusão dessas estratégias de suplementação. Assim, é importante ter um parâmetro entre o ganho de peso corporal e o seu custo, ou seja, qual o investimento necessário para a produção de $1 \mathrm{~kg}$ de peso corporal adicional.

Para isso, é de extrema importância considerar os preços dos ingredientes disponíveis, visto que nem sempre o melhor retorno econômico em um sistema de produção é proporcionado pelo melhor desempenho dos animais. Isto pode ser justificado neste estudo em que a suplementação de $6 \mathrm{~kg}$ proporcionou maior GMD e consequentemente maior ganho em arroba produzida por hectare, no entanto apresentou menor retorno econômico 
no período avaliado (Tabela 6). O melhor retorno relativo econômico e resposta produtiva (Tabela 7), retorno mensal do capital investido e menor investimento com suplementação (Tabela 6) destacaram-se para a estratégia de fornecimento de $2 \mathrm{~kg}$ de suplemento, sendo esta de maior rentabilidade econômica (Tabelas 6 e 7).

Tabela 6. Indicadores econômicos para cada estratégia de suplementação.

\begin{tabular}{|c|c|c|c|c|}
\hline \multirow{2}{*}{ Indicadores Econômicos } & \multirow{2}{*}{ SM } & \multicolumn{3}{|c|}{ Suplementos } \\
\hline & & 2 & 4 & 6 \\
\hline Peso corporal inicial $(\mathrm{kg})$ & 309,60 & 334,80 & 335,80 & 333,60 \\
\hline Ganho de peso médio diário (kg/dia) & $-0,179$ & 0,429 & 0,583 & 0,764 \\
\hline Peso corporal final & 294,60 & 370,80 & 384,80 & 397,80 \\
\hline Ganho de peso corporal (kg/84 dias) & $-15,00$ & 36,00 & 49,00 & 64,20 \\
\hline Ganho em equivalente rendimento de carcaça ${ }^{1}$ & $-0,52$ & 1,25 & 1,70 & 2,23 \\
\hline Consumo suplemento ( $\mathrm{kg} / \mathrm{dia})$ & 0,02 & 2,00 & 4,00 & 5,87 \\
\hline Custo suplemento $(\mathrm{R} \$ / \mathrm{kg})$ & 1,38 & 0,42 & 0,39 & 0,37 \\
\hline Investimento suplemento $(\mathrm{R} \$)^{3}$ & 2,32 & 69,88 & 129,42 & 180,06 \\
\hline Investimento pasto $(\mathrm{R} \$)^{3}$ & 45,19 & 45,19 & 45,19 & 45,19 \\
\hline Atualização do preço novilha $(\mathrm{R} \$)^{4}$ & 770,80 & 832,83 & 835,88 & 830,80 \\
\hline Investimento total $(\mathrm{R} \$)^{5}$ & 818,31 & 947,90 & 1010,49 & 1056,06 \\
\hline Receita $(\mathrm{R} \$)^{6}$ & 968,07 & 1218,47 & 1264,47 & 1307,19 \\
\hline Lucro $(\mathrm{R} \$)^{7}$ & 149,76 & 270,56 & 253,98 & 251,14 \\
\hline Remuneração mensal do capital investido $(\%)^{8}$ & 6,54 & 10,19 & 8,98 & 8,49 \\
\hline Ganho totalem @/ha9 & $-1,79$ & 4,30 & 5,86 & 7,67 \\
\hline
\end{tabular}

${ }^{2}$ Ganho de peso corporal*52\% de rendimento de carcaça/@(15); ${ }^{2}$ Consumo*duração do ciclo(meses)*30 dias*Custo do suplemento; ${ }^{3} 15 \%$ do valor médio da @ durante o período experimental (2,8 meses) + Custo operacional e outros custos $(=15 \% * 81,97+(0,128 *$ 84)); ${ }^{4}$ Preço da novilha aos 22 meses (IMEA) (considerado 52\% de rendimento de carcaça *valor da @ de R\$ 70,65)*[1+(0,6\% taxa de juros/100)]^duração do ciclo; ${ }^{5}$ Investimento pasto + investimento suplemento + atualização do preço da novilha; ${ }^{6}$ Venda das novilhas considerado 52\% de rendimento de carcaça *valor da @ de R\$ 94,79; ${ }^{7}$ Receita -Investimento total; ${ }^{8}$ (Lucro/Investimento total*100)/duração do ciclo; ${ }^{9}$ Equivalente carcaça*número de animais/área experimental $(1,45$ ha $)$

Fonte: Elaboração dos autores.

Tabela 7. Análise econômica em função do peso corporal adicional.

\begin{tabular}{|c|c|c|c|c|}
\hline \multirow{2}{*}{ Indicadores Econômicos } & \multirow{2}{*}{$\mathrm{SM}^{1}$} & \multicolumn{3}{|c|}{ Suplementos ${ }^{2}$} \\
\hline & & 2 & 4 & 6 \\
\hline Custo da suplementação/animal ( $\mathrm{R} \$ / 84$ dias) & 1,85 & 69,88 & 129,42 & 180,12 \\
\hline Peso corporal diário adicional (PCA) $(\mathrm{kg} / \mathrm{dia})^{3}$ & & 0,61 & 0,76 & 0,94 \\
\hline Receita $(\mathrm{R} \$)$ por $\mathrm{kg}$ de $\mathrm{PCA}^{4}$ & & 3,29 & 3,29 & 3,29 \\
\hline Retorno (R\$) do PCA em 84 dias $^{5}$ & & 167,59 & 210,31 & 260,26 \\
\hline Resposta produtiva $(\mathrm{RP})(\mathrm{kg} / \mathrm{kg})^{6}$ & & 0,30 & 0,19 & 0,16 \\
\hline Preço máximo do kg de suplemento (PMS) $(\mathrm{R} \$)^{7}$ & & 1,00 & 0,63 & 0,53 \\
\hline Custo máximo da suplementação/animal/dia $(\mathrm{R} \$)^{8}$ & & 2,00 & 2,50 & 3,10 \\
\hline Retorno econômico(R\$) ${ }^{9}$ & 0,00 & 2,40 & 1,63 & 1,44 \\
\hline
\end{tabular}

${ }^{1}$ Mistura mineral; ${ }^{2}$ Níveis de fornecimento de suplementos de 0,$55 ; 1,11$ e 1,66\% do peso corporal para 2,4 e 6 kg/animal/dia, respectivamente; ${ }^{3} \mathrm{Ganho}$ diferencial em relação ao animais suplementados com mistura mineral; ${ }^{4}$ Rendimento de carcaça de $52 \%$ e preço da arroba $(15 \mathrm{~kg})$ de $\mathrm{R} \$ 94,79$, sendo $\mathrm{RC}=(94,79 / 15) * 0,52 ;{ }^{5}$ Retorno $=(\mathrm{RC} * \mathrm{PCA} * 84$ dias $) ;{ }^{6} \mathrm{RP}=\mathrm{PCA} /$ consumo de suplemento; ${ }^{7} \mathrm{RC} * \mathrm{RP} ;{ }^{8}$ (Consumo de suplemento*PMS); ${ }^{9}$ Retorno do PCA/custos da suplementação.

Fonte: Elaboração dos autores. 
Além disso, ressalta-se a importância de avaliar a conversão de suplemento em quilograma de ganho de peso adicional, obtidos em relação aos animais suplementados apenas com mistura mineral. Apesar de a suplementação acarretar em maior despesa, todos os níveis de fornecimento de suplementos proporcionaram retorno econômico positivo (Tabela 7), ou seja, representamalternativas economicamente viáveis para a prática da suplementação no período seco do ano, pois os custos totais com o fornecimento desses suplementos foram inferiores ao preço máximo permitido, acima do qual não se viabiliza a suplementação. Deste modo, os ganhos de peso adicionais diários proporcionados com estas estratégias avaliadas foram efetivos em abonar os custos diários com a suplementação.

Desta forma, o ganho proporcionado pelo fornecimento de $6 \mathrm{~kg}$ de suplemento múltiplos demonstra a viabilidade de produzir de forma mais precoce animais em pastejo restrito na seca, ou até mesmo, possibilitando incrementos positivos na taxa de lotação e/ou produtividade das pastagens. No entanto, estas estratégias de suplementação devem ser cuidadosamente avaliadas quanto à sua duração, níveis de fornecimento e ingredientes utilizados, e devem ser adotadas como medidas paliativas em situações em que há pouca oferta de massa de forragem, para que se possa obter maior rentabilidade econômica.

A partir dos resultados da avaliação econômica foi feito simulações dos possíveis cenários, substituindo o valor da arroba e do suplemento encontrados para cada cenário gerando assim, seis simulações de viabilidade econômica para cada cenário, sendo eles o melhor, pior, médio, mais provável, otimista e pessimista (Tabelas 8 e 9).

Tabela 8. Cenários dos possíveis preços pagos ao produtor na arroba da vaca e suplementos.

\begin{tabular}{ccc}
\hline \multirow{2}{*}{ Cenários } & \multicolumn{2}{c}{ Valores em R\$ } \\
\cline { 2 - 3 } & @ Novilha & Suplemento (kg) \\
\hline Melhor & 100,00 & 0,40 \\
Pior & 55,00 & 1,30 \\
Médio & 77,50 & 0,83 \\
Mais provável & 75,00 & 0,80 \\
Otimista & 92,64 & 0,57 \\
Pessimista & 62,36 & 1,13 \\
\hline
\end{tabular}

Fonte: Elaboração dos autores.

Tabela 9. Análises econômicas dos resultados do experimento em função dos cenários simulados referentes à variação nos preços da arroba da novilha e do suplemento.

\begin{tabular}{cccc}
\hline \multirow{2}{*}{ Cenários } & \multicolumn{3}{c}{ Lucro R $\$$} \\
\cline { 2 - 4 } & $2^{1}$ & $4^{1}$ & $6^{1}$ \\
\hline Melhor & 137,50 & 115,79 & 103,11 \\
Pior & $-124,17$ & $-310,53$ & $-477,00$ \\
Médio & 6,67 & $-97,37$ & $-186,95$ \\
Mais provável & 4,26 & $-96,79$ & $-183,57$ \\
Otimista & 89,50 & 35,65 & $-7,06$ \\
Pessimista & $-84,56$ & $-247,19$ & $-391,50$ \\
\hline
\end{tabular}

${ }^{1}$ Fornecimento de 2, 4 e 6 kg de suplemento múltiplo.

Fonte: Elaboração dos autores. 
De acordo com os resultados obtidos pode-se considerar que o cenário que mais se aproximou das médias obtidas nesta pesquisa foi o cenário Melhor, entretanto, a atividade neste caso pode ser considerada como muito sensível a variações de preço.

Os cenários Médio e Mais provável para as estratégias de fornecimento de 4 e $6 \mathrm{~kg}$ de suplemento e os cenários Pior e Pessimistas de todas as estratégias apresentaram resultados negativos, ou seja, o lucro dos animais suplementados foram inferiores aos dos animais controle (sal mineral). Desta forma, pode-se interpretar que a atividade apresenta incapacidade de pagamento dos custos obtidos com o fornecimento de suplementos no período de limitada oferta de forragem.

Contudo, os cenários Melhor e Otimista apresentaram uma similaridade em relação às médias nesta pesquisa, inferindo-se que nesta ocasião, os preços fazem com que a atividade seja lucrativa de acordo com a avaliação econômica estabelecida.

De acordo com Simões e Moura (2005) este método de avaliação comparativa de diferentes cenários permite fazer algumas inferências sobre possíveis situações futuras. No entanto, não são consideradas todas as possibilidades de ocorrência dos valores para as variáveis de entrada, bem como não se pode prever a probabilidade de ocorrência de cada um deles, ou seja, a análise mostra o que pode ocorrer, mas não "garante" que um dos cenários vai ocorrer.

A comparação entre os cenários mostram certa oscilação dos resultados, ou seja, positiva quando os cenários foram o Melhor e Otimista, cobrindo os custos com o fornecimento de suplemento com certa margem favorável à atividade, e negativa quando os cenários foram os Pior e o Pessimista, ou seja, nestas ocasiões considera-se desfavorável a atividade, pois os custos com o fornecimento de suplementos são superiores a receita gerada.
Porém, deve-se considerar que esta é uma avaliação econômica referente apenas aos custos com fornecimento de suplemento, e receitas sobre o ganho obtido no período experimental. Se avaliado em um sistema completo, a suplementação em altos níveis permite redução na pressão de pastejo, maior ganho em arroba por hectare, aumento da capacidade de suporte da propriedade ao tempo que os animais são retirados das pastagens, consequentemente aumento no número de animais vendidos no ano, aumentando-se a produtividade.

\section{Conclusão}

O fornecimento de suplementos múltiplos para novilhas de corte em pastejo restrito no período da seca proporciona desempenho e retorno financeiro positivo até o fornecimento de $6 \mathrm{~kg}$ de suplemento. A estratégia de suplementação com fornecimento de $2 \mathrm{~kg}$ de suplemento múltiplo se destaca como a de melhor rentabilidade econômica.

\section{Referências}

AMETAJ, B. M.; ZEBELI, Q.; IQBAL, S. Nutrition, microbiota and endotoxin-related disease in dairy cows. Revista Brasileira de Zootecnia, Viçosa, MG, v. 39, p. 433-444, 2010. Supplement Special.

BURNS, J. C.; POND, K. R.; FISHER, D. S. Measurament of forage intake. In: FAHEY JÚNIOR, G. C. (Ed.). Forage quality, evaluation and utilization. Madison: American Society of Agronomy, Madison, 1994. p. 494-531.

CARTER, R. R.; GROVUM, W. L. A review of the physiological significance of hypertonic body fluids on feed intake and ruminal function: salivation, motility and microbes. Journal of Animal Science, Cambridge, v. 68, n. 9, p. 2811-2832, 1990.

CASALI, A. O.; DETMANN, E.; VALADARES FILHO, S. C.; PEREIRA, J. C.; HENRIQUES, L. T.; FREITAS, S. G.; PAULINO, M. F. Influência do tempo de incubação e do tamanho de partículas sobre os teores de compostos indigestíveis em alimentos e fezes bovinas obtidos por procedimento in situ. Revista Brasileira de Zootecnia, Viçosa, v. 37, n. 2, p. 335-342, 2008. 
CUNNINGHAM, K. D.; CECAVA, M. J.; JOHNSON, T. R. Nutrient digestion, nitrogen, and amino acid flows in lactating cows fed soybean hulls in place or forage or concentrate. Journal of Dairy Science, Cambridge, v. 76, n. 11, p. 3523-3535, 1993.

DETMANN, E.; PAULINO, M. F.; ZERVOUDAKIS, J. T.; VALADARES FILHO, S. C.; EUCLYDES, R. F.; LANA, R. P. QUEIROZ, D. S. Cromo e indicadores internos na determinação do consumo de novilhos mestiços, suplementados, a pasto. Revista Brasileira de Zootecnia, Viçosa, MG, v. 30, n. 5, p. 1600-1609, 2001.

EL-MEMARI NETO, A. C., ZEOULA, L. M.; CECATO, U.; PRADO, I. N.; CALDAS NETO, S. F.; KAZAMA, R.; OLIVEIRA, F. C. L. Suplementação de novilhos Nelore em pastejo de Brachiaria brizanta com diferentes níveis e fontes de concentrado. Revista Brasileira de Zootecnia, Viçosa, MG, v. 32, n. 6, p. 1945-1955, 2003.

HALL, M. B. Calculation of non-structural carbohydrate content of feeds that contain non-protein nitrogen. Gainesville: University of Florida, apr. 2000. p. A-25 (Bulletin, 339).

IPHARRAGUERRE, I. R.; CLARK, J. H. Soyhulls as an alternative feed for lactating dairy cows: a review. Journal of Dairy Science, Cambridge, v. 86, n. 4, p. 1052-1073, 2003.

IPHARRAGUERRE, I. R.; SHABI, Z.; CLARK, J. H.; FREEMAN, D. E. Ruminal fermentation and nutrient digestion by dairy cows fed varying amounts of soyhulls as a replacement for corn grain. Journal of Dairy Science, Cambridge, v. 85, n. 11, p. 2890-2904, 2002.

MERTENS, D. R. Creating a system for meeting the fiber requirements of dairy cows. Journal of Dairy Science, Cambridge, v. 80, n. 7, p. 1463-1481, 1997.

MORAES, E. H. B. K.; PAULINO, M. F.; ZERVOUDAKIS, J. T.; VALADARES FILHO, S. C.; CABRAL, L. S.; DETMANN, E.; VALADARES, R. F. D.; MORAES, K. A. K. Associação de diferentes fontes energéticas e protéicas em suplementos múltiplos na recria de novilhos mestiços sob pastejo no período da seca. Revista Brasileira de Zootecnia, Viçosa, MG, v. 35, n. 3, p. 914-920,2006.

NOCEK, J. K. Bovine acidosis: implications for laminitis. Journal of Dairy Science, Cambridge v. 80, n. 5, p. 1005-1028, 1997.

NATIONAL RESEARCH COUNCIL - NRC. Nutrients requirements of dairy cattle. 7. ed. Washington: National Academy Press, 2001. 381 p.

OWENS, F. N. Acidoses clínica e subclínica. In: SIMPÓSIO DE NUTRIÇÃO DE RUMINANTES -
SAÚDE DO RÚMEN, 3., 2007, Botucatu. Anais... Botucatu: Universidade Estadual Paulista Júlio de Mesquita Filho, 2007. p. 151-167.

PAULA, N. F.; PAULINO, M. F.; COUTO, V. R. M; DETMANN, E.; MACIEL, I. F. S.; VALENTE, É. E. L.; BARROS, L. V.; MENDES, R. K. V. Suplemento de baixo consumo para vacas de corte não-gestantes. Semina: Ciências Agrárias, Londrina, v. 35, n. 4, p. 1999-2010, 2014.

PAULINO, M. F.; DETMANN, E. D.; VALADARES FILHO, S. C. Bovinocultura funcional nos trópicos. In: SIMPÓSIO INTERNACIONAL DE PRODUÇÃO DE GADO DE CORTE, 2., 2008, Viçosa, MG. Anais... Viçosa, MG: Universidade Federal de Viçosa, 2008. v. 6, p. 275-305.

REIS, R. A.; MELO, G. M. P.; BERTIPAGLIA, L. M. A.; OLIVEIRA, A. P. Otimização da utilização da forragem disponível através da suplementação estratégica. In: REIS, R. A. et al. (Ed.). Volumosos na produção de ruminantes. Jaboticabal: FUNEP, 2005, p. 187-238.

SARWAR, M.; FIRKINS, J. L.; EASTRIDGE, M. L. Effects of varying forage or concentrate carbohydrates on nutrient digestibilities and milk production by dairy cows. Journal of Dairy Science, Cambridge, v. 75, n. 6, p. 1533-1542, 1992.

STATISTICAL ANALYSIS SYSTEM INSTITUTE SAS. SAS Institute Inc., SAS/STAT ® Software: changes and enhancements, release 8. 2, Cary, NC: SAS Institute Inc., 2001.

SILVA, D. J.; QUEIROZ, A. C. Análise de alimentos: métodos químicos e biológicos. 3. ed. Viçosa: UFV, 2002. $235 \mathrm{p}$.

SIMÕES, A. R. P.; MOURA, A. D. Análise econômica e de risco para um sistema de recria de gado de corte em regime de pastejo rotacionado na região de Aquidauana MS. In: CONGRESSO DA SOBER, 43., 2005, Ribeirão Preto, 2005. Anais... Ribeirão Preto: [s.n], 2005. CDROM.

SNIFFEN, C. J.; O'CONNOR, J. D.; VAN SOEST, P. J.; FOX, D. G.; RUSSELL, J. B. A net carbohydrate and protein system for evaluating cattle diets: II. Carbohydrate and protein availability. Journal of Animal Science, Cambridge, v. 70, n. 12, p. 3562-3577, 1992.

SOUZA, A. L.; GARCIA, R.; BERNARDINO, F. S.; CAMPOS, J. M. S.; VALADARES FILHO, S. C.; CABRAL, L. S.; GOBBI, K. F. Casca de café em dietas para novilhas leiteiras: consumo, digestibilidade e desempenho. Revista Brasileira de Zootecnia, Viçosa, v. 35, n. 3, p. 921-927, 2006. 
VALADARES FILHO, S. C.; PAULINO, P. V. R.; MAGALHÃES, K. A. Exigências nutricionais de zebuinos e tabelas de composição de alimentos (BRCORTE). Visconde do Rio Branco: Suprema Gráfica Ltda, 2006. v. 1, p. 1-142.

VAN SOEST, P. J.; ROBERTSON, J. B.; LEWIS, B. A. Symposium: carboydrate metodology, metabolism, and nutritional implications in dairy cattle. Journal Dairy Science, Cambridge, v. 74, n. 10, p. 3583-3597, 1991.
ZERVOUDAKIS, J. T.; SILVA, L. C. R. P.; SILVA, R. P.; JOSÉ NETO, A.; WERNER, J. F. K.; SILVA, R. G. F. Otimização do desempenho de bovinos por meio da suplementação à pasto. In: SIMPÓSIO MATOGROSSENSE DE BOVINOCULTURA DE CORTE, 1., 2011. Cuiabá. Anais... Cuiabá: I SIMBOVMT, 2011. p. 151-189. 